\title{
ASO Author Reflections: The Magic of Clinical Research-The Student-Led PATRONUS Study Unveils Two Patient-Reported Outcome Measures for Use in Surgical Oncology
}

\author{
CHIR-Net SIGMA Study Group and André L. Mihaljevic, M.Sc. \\ Department of Surgery, University Hospital Heidelberg, Heidelberg, Germany
}

\section{PAST}

Patient-reported outcome (PRO) measures are important in clinical trials, routine care, and quality improvement programs to capture the "personal assessment of the burden and impact of a malignant disease and its treatment". Recently, two new PRO measures have been described to capture cancer- and treatment-related symptoms and health-related quality of life: (1) the PRO version of the Common Terminology Criteria for Adverse Events (PRO$\mathrm{CTCAE}^{\mathrm{TM}}$ ) to measure symptoms; ${ }^{2}$ and (2) the computed adaptive testing version of the European Organisation for Research and Treatment of Cancer's (EORTC's) qualityof-life questionnaire (CAT EORTC QLQ-C30). ${ }^{3}$ These two PRO measures have the potential to be tailored to individual patients, cancer types, or treatment groups, but their implementation in patients undergoing cancer surgery has not yet been evaluated.

\section{PRESENT}

Overall, 303 patients undergoing major abdominal cancer surgery were enrolled at 15 sites in a prospective cohort study by a student-led clinical research network (CHIR-Net SIGMA). ${ }^{4}$ More than 100 medical students cooperatively conducted, analyzed, and reported this study under the supervision of academic surgeons. Patients reported PRO data up to 6 months postoperatively using

(c) The Author(s) 2021

First Received: 22 December 2020

Accepted: 24 December 2020;

Published Online: 22 February 2021

A. L. Mihaljevic, M.Sc.

e-mail: mihaljevic@uni-heidelberg.de electronic versions of the CAT EORTC QLQ-C30 and the PRO-CTCAE ${ }^{\mathrm{TM}}$. Twelve core cancer symptoms were assessed via the PRO-CTCAE ${ }^{\mathrm{TM}} 5$ Postoperative morbidity was recorded according to the Dindo-Clavien classification. PRO measurements were accepted by patients undergoing major abdominal surgery, as data completeness was $>80 \%$ in the immediate postoperative period. At 3-6 months postoperatively, no PRO-CTCAE symptoms differed significantly to baseline, except diarrhea. Patients reported higher 'social functioning' $(p=0.021)$ and overall quality-of-life scores $(p<0.05) 6$ months after cancer surgery compared with the baseline level. There was a lack of correlation between postoperative complications or death and any of the PRO items evaluated.

\section{FUTURE}

Our study showed the feasibility of using the CAT EORTC QLQ-C30 and the PRO-CTCAE ${ }^{\mathrm{TM}}$ in surgical oncology. These two new PRO tools are attractive for wider application in surgical oncology as they can be tailored to specific needs and situations, and can therefore allow a more personalized PRO assessment. Furthermore, both tools have already been employed in medical oncology and palliative care ${ }^{3}$ and can therefore be used to assess total cancer and treatment burden from the patients' perspective along an entire healthcare pathway. ${ }^{6}$ Future studies in more specific subgroups using disease-specific PRO items are needed to elucidate the prognostic value of the two PRO measures regarding postoperative morbidity and mortality. PATRONUS demonstrated the feasibility of student-led clinical research and uncovered important aspects for improvement in future research-based learning projects in medicine. 
FUNDING Open Access funding enabled and organized by Projekt DEAL.

DISCLOSURE André L. Mihaljevic declares no conflict of interest.

OPEN ACCESS This article is licensed under a Creative Commons Attribution 4.0 International License, which permits use, sharing, adaptation, distribution and reproduction in any medium or format, as long as you give appropriate credit to the original author(s) and the source, provide a link to the Creative Commons licence, and indicate if changes were made. The images or other third party material in this article are included in the article's Creative Commons licence, unless indicated otherwise in a credit line to the material. If material is not included in the article's Creative Commons licence and your intended use is not permitted by statutory regulation or exceeds the permitted use, you will need to obtain permission directly from the copyright holder. To view a copy of this licence, visit http://creativecommons. org/licenses/by/4.0/.

\section{REFERENCES}

1. European Medicines Agency. The use of patient-reported outcome (PRO) measures in oncology studies. Appendix 2 to the guideline on the evaluation of anticancer medicinal products in man. European Medicines Agency 2016.
2. Basch E, Reeve BB, Mitchell SA, et al. Development of the National Cancer Institute's patient-reported outcomes version of the common terminology criteria for adverse events (PROCTCAE). J Natl Cancer Inst. 2014;106(9):dju244. https://doi.org/ 10.1093/jnci/dju244.

3. Petersen MA, Aaronson NK, Arraras JI, et al. The EORTC CAT Core: the computer adaptive version of the EORTC QLQ-C30 questionnaire. Eur J Cancer. 2018;100:8-16. https://doi.org/10.10 16/j.ejca.2018.04.016.

4. CHIR-Net SIGMA Study Group, Mihaljevic AL. Multicenter prospective cohort study of the patient-reported outcome measures PRO-CTCAE and CAT EORTC QLQ-C30 in major abdominal cancer surgery (PATRONUS) - a Student-Initiated German Medical Audit (SIGMA) study. Annals of Surgical Oncology. (2021). h ttps://doi.org/10.1245/s10434-021-09646-Z

5. Reeve BB, Mitchell SA, Dueck AC, et al. Recommended patientreported core set of symptoms to measure in adult cancer treatment trials. J Natl Cancer Inst. 2014;106(7):dju129. https://doi.org/10. 1093/jnci/dju129.

6. Kluetz PG, Kanapuru B, Lemery S, et al. Informing the tolerability of cancer treatments using patient-reported outcome measures: summary of an FDA and critical path institute workshop. Value Health. 2018;21(6):742-7. https://doi.org/10.1016/j.jval.2017.09. 009.

Publisher's Note Springer Nature remains neutral with regard to jurisdictional claims in published maps and institutional affiliations. 